\title{
Effectiveness of BLS \& ACLS workshop on Cognitive, Affective and Psychomotor Skills at Rural Medical College, Loni
}

\author{
Authors \\ Dr Manju Jha ${ }^{1}$, Dr Prashant Rai ${ }^{2}$, Dr Tushar Bhavar ${ }^{3}$ \\ ${ }^{1}$ Professor \& HOD, ${ }^{2}$ MD Scholar; ${ }^{3}$ Assistant Professor \\ Dept of Anaesthesia \& Intensive Care Rural Medical College Loni \\ Corresponding Author
}

Dr Tushar Bhavar

Email:tganesh55555@gmail.com

\begin{abstract}
Background: The aim of our study was to know the effectiveness of Basic Life Support (BLS) \&Advanced Cardiovascular Life Support (ACLS) Workshop conducted at Rural Medical College, Loni.

Methods: Delegates interested for the 3-day workshop were given BLS \& ACLS manuals a month prior to workshop and instructed to attempt pretest. Pretest result, post course result and feedbacks were analyzed and comparison was done between interns, PG, Faculties and Physiotherapy students.

Results: In our study most of the participants were PG students and MBBS interns. There was significant difference of pretest results between groups, similarly post course test results were also significantly different. Comparing pre and post course performance it was found that there was highly significant difference when cognitive domain was considered and also significant improvement in the psychomotor skills.

Conclusions: ACLS and BLS workshop was found to be highly effective in improvement of knowledge and skill of the participants in managing cardiac emergencies in spite of variety of participants.

Keywords: AHA, ACLS, MBBS interns, PG students, Workshop, effectiveness, Literature, Questionere design, audiovisual, megacode.
\end{abstract}

\section{Introduction}

Despite important advances in prevention, cardiac arrest remains a substantial public health problem and a leading cause of death in many parts of the world. ${ }^{(1)}$ Cardiopulmonary resuscitation (CPR) is a procedure to support and maintain breathing and circulation for an infant, child, or adults who has stopped breathing (respiratory arrest) and/or whose heart has stopped (cardiac arrest) ${ }^{(2)}$. The theoretical knowledge and practical skills of the Basic Life Support (BLS) and the Advanced
Cardiovascular Life Support (ACLS) are among the most important determining factors of the cardiopulmonary resuscitation (CPR) success rates $^{(3)}$. Some studies have shown the presence of at least one professional trained in ACLS increase the survival of cardiac arrest victims ${ }^{(4)}$. A large number of literatures in recent years have assessed the efficacy of resuscitation training and pointed out that skills and knowledge declined over time ${ }^{(5 ; 6)}$. In other words, ACLS scores significantly decreased in the first year after certification, so 
more frequent refresher training is needed ${ }^{(7)}$. Thereby, the American Heart Association (AHA) recommends that those whose daily work requires knowledge and skills in ACLS should not only be trained in ACLS, but also be given a refresher course at least every 2 years ${ }^{(8)}$.

The goal of ACLS course is to train participants to recognize the cardiac arrest and other cardiopulmonary emergencies and save their lives through interventions by high performance team. The effectiveness of the training program was assessed in the present study.

\section{Materials and Method}

BLS \&ACLS workshops are regularly conducted at RMC, loni. 41delegates attended the workshop in August 2017. This workshops were conducted by Department of Anesthesia and Critical Care in collaboration with International Training Centers (ITC) of American heart association(AHA) and was accredited by Maharashtra Medical Council(MMC). The workshop was conducted as per AHA 2015 guidelines. Preparation for the workshop took one month which included registration for workshop, manuals were handed over to delegates at least one month before. All participants were instructed to read the manuals and attempt pretest on AHA student website. The pretest was of 60 questions divided in 3 sections of rhythm analysis, pharmacology and practical application. The pass percentage for pretest was $70 \%$. Students are instructed in which area they had scored less marks and asked to read the part again and attempt the pretest again. The result of $1^{\text {st }}$ pretest was taken into account for analysis.

We had a course director who was a senior AHA instructor and 8 instructors under the course director, the student instructor ratio of 5:1 and student manikin ratio of 3:1 was maintained. This workshops were instructor led, video based self learning under direct observation in small groups. This was a 3 day training program with 1 day of BLS and 2 days of ACLS program.

The BLS workshop was conducted on $1^{\text {st }}$ day as per the AHA guidelines. At the end of the course the cognitive domain was assessed using quantitative MCQ pattern exam of 25 marks with passing percentage of $84 \%$ i.e. 21 and above right answers. Affective and psychomotor domains were assessed using checklist guided scenario based practical examination about adult and child CPR. Candidates not able to clear the exam were remediated by course director. Total course duration was $6 \mathrm{hrs}$ including examination and remediation. Delegates were awarded with AHA BLS provider cards and certificates on successful completion of the course.

It was mandatory to complete BLS workshop before attending ACLS workshop. The ACLS workshop was also conducted according to AHA guidelines on $2^{\text {nd }}$ and $3^{\text {rd }}$ day. At the end of the course the cognitive domain was assessed using quantitative MCQ pattern exam of 50 marks with passing percentage of $84 \%$ i.e. 42 and above right answers. Affective and psychomotor domains were assessed using checklist guided scenario based skill test in which student must successfully pass High quality BLS skill test, Bag Mask ventilation skill test, learning station competencies and megacode test. Candidates not able to clear the exam were remediated by course director. Total course duration was $16 \mathrm{hrs}$ including examination and remediation. Delegates were awarded with AHA ACLS provider cards and certificates on successful completion of the course. Feedback forms were collected from all the delegates before declaring the results.

Pretest results, BLS results, ACLS results and feedback forms were analyzed.

\section{Results}

Table 1. Educational distribution

\begin{tabular}{|l|c|c|c|}
\hline & Male(\%) & Female (\%) & Total $(\%)$ \\
\hline MBBS interns & $5(12)$ & $7(17)$ & $12(29)$ \\
\hline PG residents & $19(46)$ & $3(7.3)$ & $22(53)$ \\
\hline Faculty & $3(7.3)$ & $2(4.8)$ & $5(12.1)$ \\
\hline Physiotherapy & $1(2.4)$ & $1(2.4)$ & $2(4.8)$ \\
\hline Total & $28(68)$ & $13(31)$ & 41 \\
\hline
\end{tabular}

As in table 1 we had 41 participants varying from MBBS interns to faculty. $68 \%$ of them where male participants. Among the participants 29\% 
were MBBS interns, $53 \%$ were PG students, $12.1 \%$ were faculties from designation of Registrar to Professors and $4.8 \%$ were from other specialties like Physiotherapy.

Table 2. Result analysis.

\begin{tabular}{|l|c|c|c|} 
& $\begin{array}{c}\text { Pretest } \\
\text { score(\%) }\end{array}$ & $\begin{array}{c}\text { Post course } \\
\text { score(\%) }\end{array}$ & P value \\
\hline MIBBS interns & $47.8(79.66)$ & $69(92)$ & $<0.0001$ \\
\hline PG residents & $36(60)$ & $65.4(87.2)$ & $<0.0001$ \\
\hline Faculty & $40.4(67.33)$ & $66.4(88.5)$ & 0.0005 \\
\hline Physiotherapy & $49(81.66)$ & $72(96)$ & 0.029 \\
\hline P value(ANOVA) & $<0.0001$ & $<0.0074$ & $<0.0001$ \\
\hline
\end{tabular}

As in table 2 Pretest result reveled only 17 participants scored $>70 \%$ marks. The performance of interns was good and highly significant to that of PG students $(p<0.001)$ and Physiotherapy delegates also had a significantly good performance as compared to that of PG students $(<0.05)$, applying ANOVA test it showed the difference among different groups to be highly significant $(\mathrm{p}<0.0001)$

Post test score total of 75 marks (25BLS+ 50ACLS) before remediation was compiled and it showed that: 8 delegates required remediation in theory and practical; the performance of interns was significant better as compared to PG students; rest of the intergroup comparison was insignificant; applying ANOVA it showed the difference to be significant $(\mathrm{p}<0.0074)$.

Comparing the pretest with post test results it showed the extremely significant difference in all groups of delegates. There was also significant difference in performance of CPR skills and managing a ACLS case scenarios which was assessed at the end of the workshop using a checklist based megacode practical evaluation.

At the end BLS and ACLS results were $100 \%$.

Table 3. Analysis of feedback

\begin{tabular}{|l|c|c|c|}
\hline Activity & Average(3-5) & Good (6-8) & Excellent (9-10) \\
\hline Literature & 0 & $4(9.7 \%)$ & $37(90.2 \%)$ \\
\hline $\begin{array}{l}\text { Questionnaire } \\
\text { designing }\end{array}$ & 0 & $6(14.6 \%)$ & $35(85.3 \%)$ \\
\hline $\begin{array}{l}\text { Audiovisual quality } \\
\text { Group activities/ }\end{array}$ & 0 & $5(12.1 \%)$ & $36(87.8 \%)$ \\
\hline \begin{tabular}{l} 
workstation \\
\hline Practical evaluation
\end{tabular} & 0 & $4(9.7 \%)$ & $37(90.2 \%)$ \\
\hline
\end{tabular}

Analyzing the feedbacks as shown in table 3 showed that all participants were satisfied with literature, questionnaire design, AV quality, group activity, workstations and practical evaluation.

\section{Discussion}

In spite of many advances in prevention, sudden cardiac arrest remains leading cause of death. Seventy percent of out of hospital cardiac arrest occurs in the home, $50 \%$ of them are unwitnessed and outcome is poor. Only $10 \%$ of adult patients with non-traumatic cardiac arrest who are treated by emergency medical services (EMS) survive to hospital discharge ${ }^{(9)}$. Training in ACLS is a must for all doctors and staff working in a hospital setup and those involved in management of critically ill patients.

In our study most of the participants were young recently passed MBBS and PG students, this was because they were involved in active management of patients and awareness about the training was done during their orientation program.

The pretest results showed that there was significant difference among different groups this was because interns are the group of students who are more of involved in preparation for PG exams. This also depends on the interest one takes and reads the manuals. Similar results are demonstrated in multiples studies that the knowledge level of health professionals aboutcardiopulmonary resuscitation was insufficient and routine workshops should be arranged. ${ }^{(10,11)}$

Post course testing showed that there was significant improvement in the knowledge and skills in all group of participants. This is because the AHA guidelines were followed completely and most of the delegates had came prepared theoretically so in this 3 days workshop there was more of development in psychomotor domain and revision of cognitive knowledge. There are studies showing that CPR training improves the knowledge and skills. ${ }^{(12)}$

There are many studies showing that this workshops are necessary and effective. ${ }^{(10,11,12)}$

There is strong recommendation that this training has to be repeated at regular interval and revised 
course should be taken every 2 years as skills decline over time. ${ }^{(12-14)}$

Feedbacks about Literature, questioner design, audiovisual, workstation and practical examination were of good to excellent by almost all participants as this workshop was conducted with best possible resources and senior and experienced instructors. Similar result about feedback was found in previous studies at our institute. ${ }^{(15,16)}$ There were comments for time, pass percentage, card renewal, ECG lecture to be added for which we had followed the AHA instructions and all candidates were explained importance of renewal, to come prepared with the study material thoroughly read and attempt pretest so that more of time is spent in acquiring the skills i.e. psychomotor domain. ${ }^{(13,17-19)}$

We conclude that ACLS and BLS workshop was found to be highly effective in improvement of knowledge and skill of the participants in managing cardiac emergencies in spite of variety of participants.

\section{References}

1. American Heart Association, "General concepts," in Basic Life Support for Health Care Providers, F. M. Hazinski and L. S. Hunter-Wilson, Eds., pp. 1- 6, American HeartAssociation,Dallas, Tex, USA, 2006.

2. JhumaSankar et al'Knowledge and Skill Retention of In-Service versus Preservice Nursing Professionals following an Informal Training Program in Pediatric Cardiopulmonary Resuscitation: A Repeated-Measures Quasiexperimental Study" Hindawi Publishing Corporation BioMed Research International Volume 2013, Article ID 403415, 7 pages.

3. Lima et al, "Permanent education in BLS and ACLS in nursing: "Impact on the Knowledge of Nursing Professionals" Arq Bras Cardiol 2009; 93(6) : 582-588

4. Moretti MA. Eficácia do treinamentoemsuporteavançado de vidanosresultados das manobras de ressuscitaçãocardiopulmonar
[Tese]. São Paulo: Faculdade de Medicina, Universidade de São Paulo; 2001

5. Cooper, S. \& Cade, J. (1997) Predicting survival, inhospital cardiac arrests: resuscitation survival variables and training effectiveness, Resuscitation, 35, pp. 17-22

6. Sanders, A.B., Berg, R.A., Burress, M. et al. (1994) The efficacy of an ACLS training program for resuscitation from cardiac arrest in a rural community, Ann Emerg Med, 23, pp. 56-9

7. Pottle, A. \& Brant, S. (2000) Does resuscitation training affect outcome from cardiac arrest? Accid Emerg Nurs, 8, pp. 46-51

8. Hazinski, M.F., Nadkarni, V.M., Hickey, R.W. et al. (2005) Major changes in the 2005 AHA Guidelines for CPR and ECC. Circulation. 112(suppl), pp. IV-206-IV211.

9. F. M. Hazinskiet al. "General concepts" American HeartAssociation Basic Life Suppor Provider manual 2016: 1- 6 .

10. Endale G. Gebremedhn et al. "The knowledge level of fi nal year undergraduate health science students and medical interns about cardiopulmonary resuscitation at a university teaching hospital of Northwest Ethiopia" World J Emerg Med 2014;5(1):29-34. World J Emerg Med 2016;7(4):263-269.

11. MadavanNambiaret al. "Is current training in basic and advanced cardiac lifesupport (BLS \& ACLS) effective? A study of BLS \&ACLS knowledge amongst healthcare professionals ofNorth-Kerala" World J Emerg Med 2016;7(4):263-269.

12. P. P. Saramma et al. "Assessment of longterm impact of formal certified cardiopulmonary resuscitation training program among nurses" Indian J Crit Care Med. 2016 Apr; 20(4): 226-232.

13. AHA ACLS Project team "testing and remediation" American HeartAssociation 
Advanced Cardiovascular Life Support Instructor manual 2016:45-62.

14. KentaroNogami et al. "Rapid Deterioration of Basic Life Support Skillsin Dentists With Basic Life Support Healthcare Provider" AnesthProg 2016,63:62-66.

15. DrTushar D. Bhavar et al."Experience of Participants about ACLS workshop at Rural Medical College"JMSCR June 2017;5(6): 23765-23769

16. DrTushar D. Bhavar et al."Experience of Participants about BLS workshop at Rural Medical College'IJSR July 2017;6(7): 5758

17. AHA ACLS Project team "Teaching the Course" American HeartAssociation Advanced Cardiovascular Life Support Instructor manual 2016: 27-44.

18. AHA ACLS Project team "Preparing for the Course" American HeartAssociation Advanced Cardiovascular Life Support Instructor manual 2016: 1- 26.

19. AHA ACLS Project team "Introduction" American HeartAssociation Advanced Cardiovascular Life Support Provider manual manual 2016:1-12. 